\title{
Analisis Kemampuan Pemahaman Konsep Siswa Kelas VIII SMP pada Materi Lingkaran
}

\author{
W. Eggy Yufentya*, Yenita Roza, Maimunah \\ Universitas Riau, Binawidya Km. 12.5 Simpang Baru 28293 Pekanbaru, Riau, Indonesia, \\ * Corresponding Author. E-mail: w.eggy6524@grad.unri.ac.id
}

\begin{abstract}
Abstrak
Penelitian ini bertujuan untuk mendeskripsikan kemampuan pemahaman konsep siswa untuk masing-masing indikator agar diketahui pada indikator mana siswa mengalami masalah. Metode yang digunakan dalam penelitian ini adalah deskriptif kualitatif. Berdasarkan hasil analisis data diperoleh kesimpulan bahwa siswa berkemampuan tinggi telah memiliki kemampuan pemahaman konsep yang baik sebab telah mencapai lebih dari $50 \%$ untuk setiap indikator. Sementara untuk siswa berkemampuan sedang dan rendah, memiliki pemahaman konsep yang kurang baik sebab hasil yang diperoleh kurang dari $50 \%$ untuk masing-masing indikator.
\end{abstract}

Kata kunci:Analisis, Kemampuan Pemahaman Konsep, Lingkaran

\begin{abstract}
This study aims to describe the ability to understand students' concepts for each indicator so that it is known on which indicators students experience problems. The method used in this study is descriptive qualitative. Based on the results of data analysis, it can be concluded that high-ability students have the ability to understand good concepts because they have reached more than 50\% for each indicator. While for students with moderate and low ability, they have a poor understanding of the concept because the results obtained are less than $50 \%$ for each indicator.
\end{abstract}

Keywords: Analysis, Ability to Understand Concepts, Circles

\section{PENDAHULUAN}

Matematika berkenaan dengan ide-ide, proses berpikir logis, berpola pikir deduktif dan berbagai konsep abstrak yang tersusun secara sistematis (Resta, 2018). Dalam kenyataannya, masih banyak siswa yang menganggap matematika itu cukup sulit sehingga berimbas pada hasil belajar siswa yang kurang memuaskan (Purwatiningsi, 2013).

Berdasarkan hasil wawancara kepada beberapa siswa SMP di Pekanbaru mengenai pemahamannya tentang materi lingkaran, diperoleh bahwa siswa lebih sering menghafal rumus yang diberikan tanpa mengetahui bagaimana rumus itu diperoleh. Penelitian sebelumnya oleh Tall dan Razali menemukan bahwa kesalahan dalam pemahaman konsep merupakan kesalahan yang paling banyak dilakukan siswa dalam menyelesaikan soal matematika. (Indriani, 2018). Hal ini menunjukkan bahwa siswa belum memiliki pemahaman konsep yang baik sebab siswa hanya meniru apa yang dikerjakan oleh guru dan tidak diberi kesempatan untuk membangun pengetahuannya sendiri. Padahal tujuan yang paling penting dari proses belajar mengajar adalah membangun pemahaman konsep siswa.

Siswa seharusnya dituntut untuk dapat menemukan konsep dari materi 
yang dipelajari sehingga siswa dapat lebih paham dan tidak lupa konsep dari materi sebelumnya (Fahrudin, 2018), karena keberhasilan belajar matematika siswa ditentukan oleh pemahaman konsepnya tentang matematika. (Dewi Purwanti, Dinda Pratiwi, \& Rinaldi, 2016) Siswa harus dapat mengkonstruksi pengetahuan baru dari pengetahuan yang telah dimiliki sebelumnya dalam proses pembelajaran matematika.

Pemahaman konsep sangat penting dimiliki siswa sehingga proses belajar yang dialami siswa bukan hanya sekedar menghafal dan pemberian soalsoal latihan. Jika seorang siswa hanya menghafal tanpa mengaitkan konsep dengan konsep lain maka proses maupun hasil belajarnya tidak akan bermakna sama sekali baginya (Fadjar Shadiq dan Nur Amini, 2011). Hal ini dikarenakan antar konsep dalam matematika sangat berkaitan satu dengan yang lainnya yang apabila kemampuan dasar belum dipahami dengan baik maka siswa akan kesulitan dalam merancang dan menyelesaikan permasalahan dalam matematika (Netriwati, 2018). Untuk itu diperlukan kajian pembahasan mengenai masalah pada kemampuan konsep siswa.

Beberapa penelitian terdahulu telah banyak dilakukan penelitiam dengan tujuan meningkatkan pemahaman konsep siswa (Argikas \& Khuzaini, 2016; Astriani, 2017; Haryanti \& Ardi Saputro, 2016; Hidayat \& Nurrohmah, 2016; Kurniati, 2015; Mustofa, Susilo, \& Muhdhar, 2016; Nurintasari, 2015; Rukmansyah, 2015; Ulfaeni, Wakhyudin, \& Saputra, 2017). Namun belum terdapat penelitian yang mencoba mendeskripsikan kemampuan pemahaman konsep siswa pada materi lingkaran. Perbedaan antara penelitian ini dan penelitian sebelumnya adalah bahwa penelitian ini difokuskan pada deskripsi kemampuan pemahaman konsep siswa kelas VIII SMP Negeri 20 Pekanbaru pada materi lingkaran untuk masing-masing indikator agar diketahui pada indikator mana siswa mengalami masalah.

\section{METODE PENELITIAN}

Metode penelitian yang digunakan dalam penelitian ini adalah deskriptif kualitatif. Subjek dalam penelitian ini adalah siswa kelas VIII SMP Negeri 20 Pekanbaru sebanyak 23 orang yang terdiri dari 6 siswa berkemampuan rendah, 11 siswa berkemampuan sedang dan 6 siswa berkemampuan tinggi. Teknik pengumpulan data dilakukan dengan menggunakan tes tertulis dan wawancara. Analisis data dilakukan berdasarkan pancapaian indikator untuk melihat pemahaman konsep siswa. Indikator yang diukur pada penelitian kali ini adalah adalah (1)menyajikan konsep dalam berbagai bentuk representasi matematis, (2)menggunakan dan memanfaatkan serta memilih prosedur atau operasi tertentu, dan (3)mengaplikasikan konsep atau algoritma pada pemecahan masalah.

\section{HASIL DAN PEMBAHASAN}

Terdapat 4 soal yang diberikan pada siswa yang tiap soalnya mengukur ketiga indikator pemahaman konsep. Soal nomor 1 mencari besar sudut pusat dengan menerapkan konsep besar sudut-sudut keliling yang menghadap busur yang sama; soal nomor 2 mencari luas juring jika diketahui besar dua buah sudut pusat dan luas salah satu juring dalam sebuah lingkaran; soal nomor 3 mencari panjang busur jika diketahui besar sudut pusat dan jari-jari lingkarannya dan soal nomor 4 menerapkan konsep panjang busur lingkaran dalam masalah kontekstual. Hasil analisis dari jawaban siswa dapat dilihat pada Tabel 1 berikut. 
Desimal, 2 (3), 2019 - 199

W. Eggy Yufentya, Yenita Roza, Maimunah

Tabel 1. Persentase Siswa yang Menjawab Benar

\begin{tabular}{llccc}
\hline No & \multicolumn{1}{c}{ Indikator } & \multicolumn{1}{c}{$\begin{array}{c}\text { Persentase siswa yang } \\
\text { menjawab benar }\end{array}$} \\
$\mathbf{1}$ & $\begin{array}{l}\text { Menyajikan konsep dalam berbagai bentuk representasi } \\
\text { matematis }\end{array}$ & 58.33 & 47.73 & 34.78 \\
$\mathbf{2}$ & $\begin{array}{l}\text { Menggunakan dan memanfaatkan serta memilih prosedur } \\
\text { atau operasi tertentu }\end{array}$ & 70.73 & 45.45 & 21.74 \\
$\mathbf{3}$ & $\begin{array}{l}\text { Mengaplikasikan konsep atau algoritma pada pemecahan } \\
\text { masalah }\end{array}$ & 65.91 & 31.52 & 19.57 \\
\hline
\end{tabular}

Berikut adalah salah satu contoh jawaban siswa berkemampuan sedang pada soal nomor 1 .

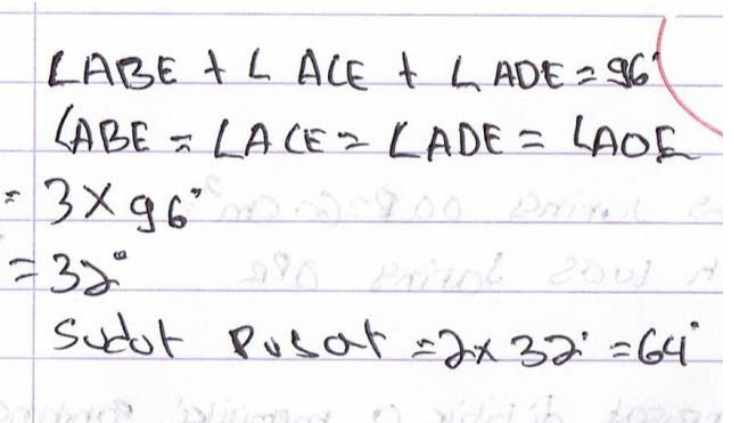

Gambar 1. Contoh hasil kerja siswa berkemampuan sedangpada soal nomor 1

Pada soal nomor 1, diberikan gambar sebuah lingkaran dan diketahui jumlah 3 buah sudut keliling yang menghadap busur yang sama yaitu ? $A B E$, ? $A C E$ dan ? $A D E$ adalah $96^{\circ}$ dan ditanya besar sudut pusat yang menghadap busur yang sama pada lingkaran tersebut, yaitu ? $A O E$. Siswa belum mampu merepresentasikan konsep dari gambar ke bentuk model matematika nya dengan benar. Siswa menyatakan bahwa besar ? $A B E=$ ? $A C E=$ ? $A D E=$ ? $A O E$. Setelah diwawancara, diketahui bahwa siswa salah tulis. Seharusnya ia menuliskan ? $A B E=$ ? $A C E=$ ? $A D E=\frac{1}{2}$ ? $A O E$ ， namun lupa menuliskan $1 / 2$. Kemudian siswa juga belum dapat menggunakan prosedur atau operasi tertentu dengan benar, terbukti dari jawaban $3 \times 96=$ 32 yang dibuat siswa. Peneliti mewawancarai siswa mengenai jawabannya tersebut, diperoleh bahwa siswa memang tidak mengetahui hubungan antara beberapa sudut keliling yang saling menghadap busur yang sama. Siswa hanya tahu bahwa besar sudut pusat sama dengan dua kali sudut keliling, sehingga pada indikator mengaplikasikan konsep untuk pemecahan masalah juga siswa masih belum tepat.

Berikutnya adalah jawaban siswa berkemampuan rendah untuk soal nomor 2 .

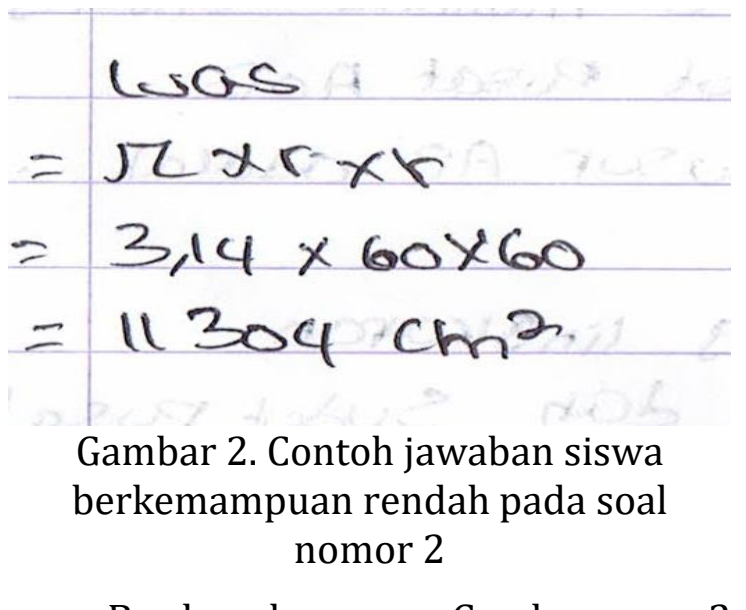

Berdasarkan Gambar 2 menunjukkan bahwa siswa tersebut tidak dapat menyajikan konsep ke berbagai representasi matematis sebab siswa salah dalam membuatkan model matematika dari gambar yang diberi. Siswa juga belum mampu memilih dan menggunakan prosedur serta mengaplikasikan konsep untuk menyelesaikan masalah tersebut dengan baik. Siswa hanya mencari luas lingkaran, padahal yang ditanyakan luas juringnya. Ketika dilakukan wawancara, 
Desimal, 2 (3), 2019 - 200

W. Eggy Yufentya, Yenita Roza, Maimunah

siswa mengatakan bahwa ia lupa rumus mencari luas juring. Sehingga daripada kertas jawabannya kosong, ia tuliskan saja luas lingkaran yang ia hafal rumusnya.

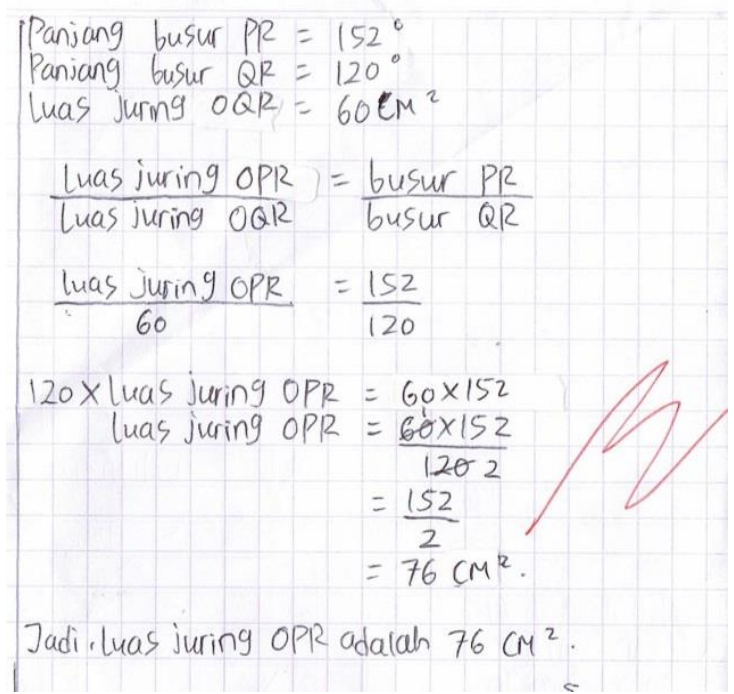

Gambar 3. Contoh jawaban siswa berkemampuan tinggi pada soal nomor 2

Siswa berkemampuan tinggi dapat menyajikan konsep, memilih dan menggunakan prosedur serta mengaplikasikan konsep dengan baik dan sistematis.

Jawaban salah satu siswa berkemampuan rendah pada soal nomor 3 seperti pada gambar di bawah.

Panjang busur $\begin{aligned} A B & =\frac{72}{360} \times K 0 \\ & =\frac{1}{5} \times 2 \pi r \\ & =\frac{1}{2} \times 2 \times 3 .\end{aligned}$

Gambar 4. Contoh jawaban siswa berkemampuan rendah pada soal nomor 3

Pada soal nomor 3 diketahui panjang jari-jari serta besar sudut pusat lingkaran dan yang ditanyakan adalah panjang busur AB. Siswa mampu menyajikan konsep ke berbagai representasi matematis dengan baik, namun belum dapat menggunakan prosedur atau operasi tertentu serta mengaplikasikan konsep untuk pemecahan masalah dengan baik.

Berdasarkan hasil wawancara, siswa salah tulis jari-jari lingkaran, seharusnya 35 namun tertulis 3 . Kemudian untuk nilai $\pi$, siswa mengatakan bahwa ia masih bingung apakah 3,14 atau $\frac{22}{7}$ yang harus digunakan. Jawaban siswa tersebut menunjukkan bahwa ia belum memahami konsep lingkaran dengan baik.

Pada soal nomor 4, diberikan sebuah masalah kontekstual yang meminta siswa untuk menentukan panjang kawat yang harus dipasangkan di sekeliling taman sebanyak dua kali putaran. Diketahui pada soal besar sudut pusatnya dan panjang tepian taman, yang dalam hal ini disebut jarijari. Berikut jawaban siswa berkemampuan sedang.

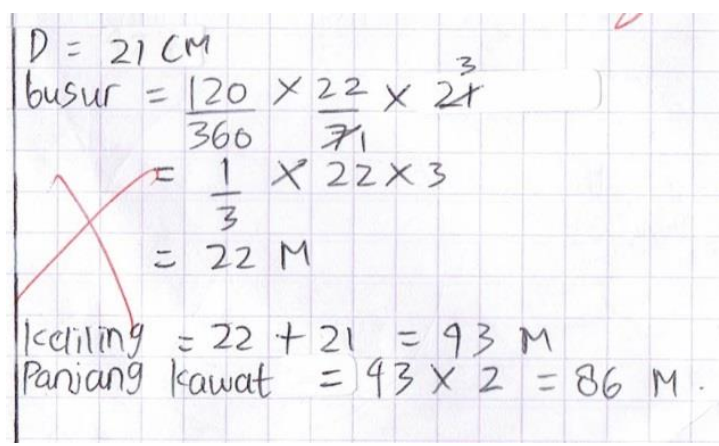

Gambar 5. Contoh jawaban siswa berkemampuan sedang pada soal nomor 4

Siswa mampu menyajikan konsep ke berbagai representasi matematis dengan baik. Siswa juga mampu memilih dan menggunakan prosedur atau operasi tertentu, namun siswa belum dapat mengaplikasikan konsep pada pemecahan masalah dengan baik. Hasil wawancara peneliti dengan siswa diketahui bahwa siswa tersebut tidak teliti, ia lupa menambahkan panjang jari-jarinya untuk menentukan keliling 
Desimal, 2 (3), 2019 - 201

W. Eggy Yufentya, Yenita Roza, Maimunah

taman tersebut. Siswa hanya menambahkannya sekali, padahal seharusnya dua kali.

Dari data yang diperoleh, dapat disimpulkan bahwa pemahaman konsep siswa masih kurang dari 50\% dan berdasarkan hasil wawancara juga diketahui bahwa siswa belum memiliki pemahaman yang baik tentang materi lingkaran. Kurangnya partisipasi aktif siswa dalam membangun konsepnya sendiri dan hanya menghafal rumus yang diberikan merupakan salah satu penyebabnya. Sementara kemampuan siswa untuk turut membangun sendiri pengetahuannya dan tidak bergantung sepenuhnya dengan guru adalah salah satu cara untuk meningkatkan kemampuan pemahaman konsep siswa. Kegiatan belajar mengajar yang hanya memberi latihan-latihan soal yang hasilnya dapat ditemukan secara prosedural juga menjadi penyebab lainnya. Sebab secara tidak langsung guru melatih siswa hanya untuk keterampilan berhitung dan siswa memiliki kecendrungan untuk menghafal rumus yang ada. Mampu menyelesaikan atau memecahkan masalah matematis memang merupakan salah tujuan pembelajaran matematika, namun hal itu dapat dicapai ketika siswa memiliki pemahaman konsep yang baik.

\section{SIMPULAN DAN SARAN}

Berdasarkan hasil dan pembahasan disimpulkan bahwa siswa berkemampuan tinggi telah memiliki kemampuan pemahaman konsep yang baik sebab telah mencapai lebih dari $50 \%$ untuk setiap indikator. Sementara untuk siswa berkemampuan sedang dan rendah, memiliki pemahaman konsep yang kurang baik sebab hasil yang diperoleh kurang dari 50\% untuk masing-masing indikator.
Berdasarkan kesimpulan tersebut, penulis menyarankan bahwa agar guru membiasakan siswa untuk menyajikan konsep ke berbagai bentuk representasi matematika saat proses pembelajaran dan memberi kesempatan kepada siswa untuk dapat mengaplikasikan konsep yang dalam menyelesaikan masalah secara benar dan sistematis.

\section{DAFTAR PUSTAKA}

Argikas, T. B., \& Khuzaini, N. (2016). Penerapan model pembelajaran Reciprocal Teaching untuk meningkatkan pemahaman konsep matematika siswa kelas vii SMP negeri 2 depok. Jurnal Mercumatika, 1(1), 67-79.

Astriani, L. (2017). Pengaruh pembelajaran reciprocal teaching terhadap kemampuan pemahaman konsep matematika ditinjau dari kemampuan awal matematika siswa. Jurnal Pendidikan Matematika Dan Matematika, 3(1), 77-85.

Dewi Purwanti, R., Dinda Pratiwi, D., \& Rinaldi, A. (2016). Pengaruh Pembelajaran Berbantuan Geogebra Terhadap Pemahaman Konsep Matematis Ditinjau Dari Gaya Kognitif. Al-Jabar, 7(1), 115122.

Fahrudin. (2018). Pembelajaran Problem Solving Modifikasi untuk Meningkatkan Kemampuan Pemahaman Konsep Matematis Siswa SMP 1. Desimal: Jurnal Matematika, 1(2), 181-189.

Haryanti, F., \& Ardi Saputro, B. (2016). Pengambangan Modul Matematika Berbasis Discovery Learning Berbantuan Flipbook Maker Untuk Meningkatkan Kemampuan Pemahaman Konsep Pada Materi Segitiga. Jurnal Pendidikan Matematika, I(2), 147-161.

Hidayat, R., \& Nurrohmah. (2016). Analisis Peningkatan Kemampuan 
Desimal, 2 (3), 2019 - 202

W. Eggy Yufentya, Yenita Roza, Maimunah

Pemahaman Konsep Matematis Siswa MTs Lewat Penerapan Model Pembelajaran Problem Based Learning Berbantuan Software Geogebra Berdasarkan Kemampuan Awal Matematika. JPPM, 9(1), 12-19.

Indriani, L. F. (2018). Kemampuan Penalaran Matematis dan Habits of Mind Siswa SMP dalam Materi Segiempat dan Segitiga. Jurnal Math Educator Nusantara, 4(2), 87-94.

Kartika, Y. (2018). Analisis kemampuan pemahaman konsep matematis peserta didik kelas vii smp pada materi bentuk aljabar. Jurnal Pendidikan Tambusai, 2(58), 777785.

Kurniati, T. (2015). Penerapan Model Siklus Belajar 5E Terhadap Pemahaman Konsep Biologi Umum Dan Kemampuan Aplikasi Sains Mahasiswa Pendidikan Biologi. Jurnal Pengajaran Matematika Dan Ilmu Pengetahuan Alam, 20(1), 6064.

Murizal, A. (2012). Pemahaman Konsep Matematis dan Model Pembelajaran Quantum Teaching. Jurnal Pendidikan Matematika, 1(1), 1923.

Mustofa, Z., Susilo, H., \& Muhdhar, M. H. I. Al. (2016). Penerapan Model Pembelajaran Problem Based Learning Melalui Pendekatan Kontekstual Berbasis Lesson Study Untuk Meningkatkan Kemampuan Memecahkan Masalah Dan Hasil Belajar Kognitif Siswa SMA. Jurnal Pendidikan: Teori, Penelitian, Dan Pengembangan, 1(5), 885-889.

Netriwati. (2018). Penerapan Taksonomi Bloom Revisi untuk Meningkatkan Kemampuan Pemahaman Konsep Matematis. Desimal: Jurnal Matematika, 1(3), 347-352.

Nurintasari, A. (2015). Pengembangan

Lembar Aktivitas Siswa (LAS)
Matematika Berbasis Metode Penemuan Terbimbing Untuk Memfasilitasi Pencapaian Pemahaman Konsep dan Keaktifan Belajar Siswa Kelas VII pada Pokok Bahasan Segi Empat. Universitas Islam Negeri Sunan Kalijaga.

Purwatiningsi, S. (2013). Penerapan Metode Penemuan Terbimbing Untuk Meningkatkan Hasil Belajar Siswa Pada Materi Luas Permukaan dan Volume Balok. Jurnal Elektronik Pendidikan Matematika Tadulako, 1(1).

Resta, E. L. (2018). Kemampuan pemahaan matematis siswa pada materi segiempat. Jurnal Pendidikan Tambusai, 2(1), 17101718.

Rukmansyah, E. T. (2015). Penggunaan Media Instan Dan Pendekatan Somatic Auditory Visual Intellectual (SAVI) Untuk Meningkatkan Pemahaman Konsep Kalor. Jurnal Pengajaran MIPA, 20(1), 43-47.

Ulfaeni, S., Wakhyudin, H., \& Saputra, H. J. (2017). Pengembangan Media Monergi ( Monopoli Energi) Untuk Menumbuhkan Kemampuan Pemahaman Konsep IPA Siswa SD. Profesi Pendidikan Dasar, 4(2), 136-144. 